\title{
The E-2-hexenal play critical role in carotenoids activated inner membrane structures transformation in the chloroplasts
}

\author{
Xince Wang ${ }^{1}$, Fei Sun ${ }^{1}$, Cong Han ${ }^{1}$, Qingmin Chen ${ }^{2}$, Xiaoying Yang ${ }^{1}$, Jianfeng Cheng ${ }^{3}$, Lili \\ $\mathrm{Zhu}^{3}$, Jingjing $\mathrm{Liu}^{3}$, Feifei $\mathrm{Tan}^{4}$, Maorun $\mathrm{Fu}^{1}$, and Bo $\mathrm{Cui}^{1}$ \\ ${ }^{1}$ Qilu University of Technology \\ ${ }^{2}$ Shandong Agriculture and Engineering University \\ ${ }^{3}$ Jiangxi Agricultural University \\ ${ }^{4}$ Beijing Science and Technology Publishing Co Ltd
}

May 5, 2020

\begin{abstract}
The carotenoids start the inner membrane structures (IMS) transformation of chloroplasts during colour transformation in tomatoes, but the mechanism remains unclear. E-2-hexenal $(\mathrm{E} 2 \mathrm{H})$ may function downstream of carotenoids to regulate the transformation. In the tomatoes treated with $\mathrm{E} 2 \mathrm{H}$, colour transformation was inhibited and the colour transformation cannot be initiated by ethylene (ET) again, whereas in the ET pretreated tomatoes, the E2H lost the function of inhibition. Therefore, the E2H function downstream of ET. The electron micrographs showed the exogenous E2H accelerated the IMS transformation before enough carotenoids accumulated. Therefore, the E2H may acted downstream of the carotenoids starting the IMS transformation. The contents and the biosynthesis locations of chlorophyll, lycopene and $\beta$-carotene supported the E2H accelerated IMS transformation. The E2H expedited LOXC expression caused advanced free linolenic acids consume, E2H also accelerate the release of linolenic acids directly, thus the composition changes altered the IMS. The HPL expression patterns may related with the endogenous E2H feedback balance. The titratable acids, ascorbic acids, soluble solids and malondialdehyde contents also supported the hypothesis. Above all, E2H mediated the carotenoids started IMS transformation. Novel function of the E2H was proposed. Keywords: tomato, E-2-hexenal, chloroplasts, chromoplast, plastids, colour, carotenoid
\end{abstract}

\section{Introduction}

Colour transformation and volatiles emitting both contribute to tomato quality, they are often accompanied with each other. Moreover, both the carotenoids and green leaf volatile (GLVs) are synthesized in the plastids (Barr, White, Chen, Bae \& Rodermel, 2004, Bonaventure, Schuck \& Baldwin, 2011). In this study we are trying to establish a regulatory relationship between colour transformation and volatiles emitting.

Before the inner membrane structures (IMS) of chloroplasts transformation, carotenoids synthesis has started in grana and stroma thylakoids and then packed into IMS (Schweiggert, Steingass, Heller, Esquivel \& Carle, 2011, Sun, Yuan, Cao, Yazdani, Tadmor \& Li, 2018). The chromoplast characteristic structures including tubular elements (te), plastoglobules (pg) and crystal remnants (cr) have been reported to be induced by the early accumulated carotenoids (Lu, Wang, Yin, Zhong, Grierson, Chen \& Xu, 2017, Schweiggertet al. , 2011). Howerver, the mechanism of the carotenoids started IMS transformation in the chloroplasts still remains unclear (Sun \& Li, 2020).

Based on our research, one of the GLVs, E -2-hexenal (E2H) may function downstream of carotenoids to regulate the transformation. $\mathrm{E} 2 \mathrm{H}$ is one of the most abundant volatiles in fruits including tomato (Ham- 
merbacher, Coutinho \& Gershenzon, 2019). The biosynthesis of E2H consume the membrane lipids and energies, therefore the function of E2H must be beneficial to survival (Mumm, Posthumus \& Dicke, 2008). Most plants, including single-cell algae, have evolved the E2H synthesis and release mechanisms (Ma, Xiao, Li, Li, Shi, Liang, Lu \& Chen, 2011). But according to the theory of evolution, algae did not seem to use E2H as allelopathic molecules to react with biotic stress signals because biotic stress didn't exist then. Different from the allergic effects previously reported, E2H is proposed to involve in the regulation of tomato colour transformation in this study.

In this study, we tried to verify the hypothesis that $\mathrm{E} 2 \mathrm{H}$ play critical role in activating the IMS transformation in chloroplasts.

\section{Materials and methods}

\subsection{E-2-Hexenal treatment and sampling}

Tomato (solanum lycopersicum ) fruits were harvested in Jinan. The developmental status was strict controlled, only the tomatoes with slight reddish colour were selected. Tomato fruits were transported to the laboratory within 1 hour, sterilization with $2 \%$ sodium hypochlorite for $2 \mathrm{~min}$. The tomatoes were divided into different groups and storage at $20^{\circ} \mathrm{C}$, each group contained no less than 30 fruits.

When tomatoes were treated with E-2-Hexenal (Aladdin, Shanghai, China), they were placed in $50 \mathrm{~L}$ plastic sealed boxes. Different volumes of $E$-2-Hexenal liquid were added to filter paper in the petri dish and placed in boxes to achieve environmental concentrations at $0.5,2.5,12.5$ and $25 \mu \mathrm{L} \mathrm{L}^{-1}$ as liquid volume / gas volume. The treatments were named as E2H (0.5), E2H (2.5), E2H (12.5) and E2H (25) separately.

When tomatoes were treated with combined $E$-2-Hexenal and ethylene, tomatoes were treated in the same $50 \mathrm{~L}$ plastic sealed boxes with $E-2$-Hexenal and ethylene $\left(12 \mathrm{mg} \mathrm{L}^{-1}\right)$ sequentially [ET $(12 \mathrm{~h})$ and then E2H $(12 \mathrm{~h})$ or E2H (12 h) and then ET (12 h)] or simultaneously.

The pericarp tissues of the tomatoes were sampled at $0,6,18,36$ and $72 \mathrm{~h}$, then quickly frozen with liquid nitrogen and stored at $-80^{\circ} \mathrm{C}$.

\subsection{Transmission electron microscopy (TEM)}

The tomatoes were treated with E2H for $24 \mathrm{~h}$ at the concentration of $2.5 \mu \mathrm{L} \mathrm{L}^{-1}$. After $72 \mathrm{~h}$, tissues of the pericarp close to the skins were collected. All tissues were cut with a razor blade to sizes of about $0.5 \mathrm{~mm}$ $\times 2.0 \mathrm{~mm}^{2}$ and immediately treated with $5 \%$ glutaraldehyde $(0.1 \mathrm{M}$ sodium phosphate buffer, $\mathrm{pH} 7.4)$ for 1 day at $4^{\circ} \mathrm{C}$. The sodium cacodylate buffer $(0.1 \mathrm{M})$ was used for washing the tissues three times for $20 \mathrm{~min}$. The post fixing was performed with $1 \%$ osmium tetraoxide for $1 \mathrm{~h}$ at $4 \operatorname{deg}$. The tissues after incubation for $1 \mathrm{~h}$ with $1 \%$ uranyl acetate at $4 \operatorname{deg} \mathrm{C}$ were dehydrated in graded dimethyl ketone and then transferred into Epon 812 (Plano, Marburg, Germany). A rotating microtome blade was used to cut $65 \mathrm{~nm}$ thin sections which were mounted subsequently onto the copper grids. The section staining and counter staining was performed using uranyl acetate (5\%) and Reynold's lead citrate, respectively. The section examination was carried out under Jeol-Jem 1011 transmission electron microscope (Jeol, Tokyo, Japan) (Schweiggert et al. , 2011).

\subsection{Pigment contents}

The 3nh Colorimeter (3nh, Shenzhen, China) were used to detect the $\mathrm{a}^{*}$ values of the tomatoes. Data was obtained by detecting the four sides of the fruit equator and $a^{*}$ values were calculated as the average of the four data. All values were in triplicate. 
The fruit tissues $(0.2 \mathrm{~g})$ were extracted in $80 \%$ ice-cold acetone. Total chlorophyll contents were measured spectrophotometrically by reading absorbance at $663\left(\mathrm{~A}_{645}\right)$ and $645 \mathrm{~nm}\left(\mathrm{~A}_{663}\right)$. The total chlorophyll quantities were calculated as (Arnon, 1949):

\section{Total chlorophyll contents $=20.29 A_{645}+8.05 A_{663}$}

The fruit tissues $(1.0 \mathrm{~g})$ were ground and homogenized with $2 \mathrm{~mL}$ ice-cold acetone and $2 \mathrm{~mL}$ dichloromethane. The extraction was repeated until the supernatant appeared colorless. Combined the supernatants and diluted to $25 \mathrm{~mL}$ and then filtered. The extractions should avoid the lights all the time.

Carotenoids were separated by HPLC (Shimadzo, Tokyo, Japan) using a Zorbax SB-C18 column (silica 5 $\mu \mathrm{m}, 4.6 \mathrm{~nm} \times 250 \mathrm{~nm}$ ) (Agilent, Santa Clara, USA).

The mobile phase consisted of acetonitrile: $\mathrm{H}_{2} \mathrm{O}$ (9:1) (solvent A) and 100\% ethyl acetate (solvent B), which were used in a linear gradient between $\mathrm{A}$ and $\mathrm{B}$ for $30 \mathrm{~min}$, at a flow of $1 \mathrm{~mL} \mathrm{~min}{ }^{-1}$. The carotenoids were detected using UV detector at the wavelength of $475 \mathrm{~nm}$. The carotenoids were confirmed by their retention times compared to the lycopene and $\beta$-carotene standard compounds. Peak areas of the standard compounds were used to quantitative analysis the carotenoids in the samples (Ronen, Cohen, Zamir \& Hirschberg, 1999).

\subsection{LXOC and HPL gene expression}

Total RNA was isolated using the Plant Total RNA Isolation Kit Plus (Foregene, Chengdu, China) according to the manufacturer's instructions. cDNA was synthesized using M5 Superfast qPCR RT Kit (Juhemei, Beijing, China) (Yang, Wang, Tan, Fu \& Sun, 2019). Quantitative PCR was performed using the SYBR Green PCR kit (Juhemei, Beijing, China) on a PTC-200 real time PCR system: $95{ }^{\circ} \mathrm{C}$ for 10 min followed by 30 cycles of $95{ }^{\circ} \mathrm{C}$ for $15 \mathrm{~s}$, and $60{ }^{\circ} \mathrm{C}$ for $60 \mathrm{~s}$. Gene-specific primers were listed in Table 1 . The Actin was used as a housekeeping gene. Calculation of the relative quantification was performed by the comparative $2^{-\Delta \Delta^{n}}{ }_{\mathrm{T}}$ method (Livak \& Schmittgen, 2001). All reactions were in triplicate.

\subsection{The titratable acids, ascorbic acids, soluble solids and malondialdehyde contents}

The titratable acidity (TA) and soluble solid contents (SSC) were analyzed according to the previously reported method (Sun, Zhang, Guo, Yu \& Chen, 2013). Nine fruits were selected to determine the TA and SSC. The pericarp tissues were homogenized in a mortar, and then homogenates were filtered. Obtained juice was used to determine TA and SSC. The TA was analyzed by $0.1 \mathrm{~mol} \cdot \mathrm{L}-1 \mathrm{NaOH}$ adding dropwise to the juices until the solution reached a $\mathrm{pH}$ of 8.1. The SSC was analyzed with a held-held refractometer (Atago, Tokyo, Japan).

The ascorbic acids (Vc) and malondialdehyde (MDA) contents were analyzed according to the previously reported method (Wei, Lv, Xia, Tan, Sun, Yu, Jia \& Cheng, 2017). Tomato pericarp tissues (5 g) were homogenized with $10 \mathrm{~mL}$ of $5 \%$ (w/v) metaphosphoric acid using a T25 homogenizer (IKA, German) at speed 6 (highest). The supernatant was used for ascorbic acid measurements with the 2, 4-dinitrophenylhydrazine method. After a sulfuric acid (85\%, v/v)-assisted colour reaction, spectrophotometry was used to determine the ascorbic acid content at $500 \mathrm{~nm}$. For MDA, the absorbencies of the aqueous phase at $450 \mathrm{~nm}, 532 \mathrm{~nm}$ and $600 \mathrm{~nm}$ were measured. The MDA content in the aqueous phase was calculated according to the following formula (Wei et al. , 2017):

$\operatorname{MDA}\left(\mathrm{mol} \mathrm{L}^{-1}\right)=\left[6.45 \times\left(\mathrm{A}_{532}-\mathrm{A}_{600}\right)-0.56 \times \mathrm{A}_{450}\right] \times 10^{-6}$. 


\subsection{Statistical analysis}

Data were subjected to Duncan's Multiple Range Test to determine significant differences $(P<0.05)$ (Wei et al. , 2017).

\section{Results}

\subsection{Effects of E-2-hexenal on tomoto colour development}

Postharvest colour developments in response to $E$-2-hexenal $(\mathrm{E} 2 \mathrm{H})$ with different concentrations $(0.5-25 \mu \mathrm{L}$ $\left.\mathrm{L}^{-1}\right)$ were observed at $72 \mathrm{~h}$. Tomatoes treated with E2H showed restrained coloration in concentrationdependent patterns (Figure 1A). The pericarps colour development was totally inhibited from the outermost to the innermost by $\mathrm{E} 2 \mathrm{H}$, but the columellas were not affected by the E2H treatments (Figure 1B). In the skins, patchy green areas were separated by red areas (Figure 1C).

\subsection{Effects of combined E-2-hexenal and ethylene on tomato colour develop- ment}

$\mathrm{E} 2 \mathrm{H}, \mathrm{ET}$, combined E2H and ET, and different priorities of E2H and ethylene (ET) treatments on the tomatoes showed different patterns at $72 \mathrm{~h}$. Tomato treated with ET $(12 \mathrm{~h})$ and then E2H $(12 \mathrm{~h})$ showed red colour like the ET or the control group. Tomato treated with E2H (12 h) and then ET (12 h), as well as the combined $\mathrm{E} 2 \mathrm{H}$ and ET group showed inhibited colour development like the E2H group (Figure 2).

\subsection{Effects of E-2-hexenal on the transform of chloroplast to chromosome}

During the transformation of chloroplast to chromosome, the IMS (inner membrane structure) including inner envelope membrane (IEM) and the thylakoid membranes proliferated disappeared, and produced new structures such as tubular elements (te), plastoglobules (pg) and crystal remnants (cr) via membrane fusion or vesicles budding (Figure 3B-D). Based on the dynamics of im, te, pg and cr during the transform processes of chloroplast to chromosome (Figure 3I), four stages (S1: chloroplast; S2: transition states 1; S3: transition states 2 and S4: chromosome) of the plastids were suggested in this study, for example, The im vanishes at S3; te and pg emerge at S2; cr emerges at S4. (Fig. 3I).

In the control group, all the plastids observed by TEM were statistically analyzed (Figure 3A-D). The proportions of plastids in S1, S2, S3 and S4 were 35\%,17\%, $17 \%$ and $31 \%$ separately. No plastids in the $\mathrm{S} 1$ and $\mathrm{S} 2$ states were detected in the $\mathrm{E} 2 \mathrm{H}$ group, and the proportions of $\mathrm{S} 3$ and $\mathrm{S} 4$ were $44 \%$ and $56 \%$, respectively (Figure $3 \mathrm{E}$ and $\mathrm{F}$ ).

The transform from S1 to S4 in the control group were programmed, im disappeared, te appeared, pg gradually accumulated, and further cr accumulated (Figure 3A-D). However, most of the plastids in the E2H group completed transformation without sufficient accumulation of pg and no cr observed (Figure 3E and F). Therefore, the pg count per plastid in the E2H group was significantly lower than the control (Figure $3 \mathrm{~J})$.

\subsection{Effects of E-2-hexenal on pigment contents}

The $\mathrm{a}^{*}$ values indicate red-green difference, lower value indicates the fruit colour close to green, higher value indicates the fruit colour close to red (Gao, Liu, Kan, Chen \& Chen, 2019). The a* values of the control increased during 18-72h. Both E2H (2.5) and E2H (12.5) treatment decelerated the increase speed of the $\mathrm{a}^{*}$ values. More obviously, no a* value increase was observed in the E2H (12.5) group (Figure 4A). 
The chlorophyll is the main pigment of green tomatoes and the concentrations decreased during postharvest ripening in the control group in 18-72 h. Both l E2H (2.5) and E2H (12.5) decelerated the decrease speed of chlorophyll contents. In 36-72 h, E2H (12.5) group showed more obvious effects then the E2H (2.5) group (Figure 4B).

The $\beta$-carotene and lycopene are two pigments of red tomatoes and the concentrations increased during postharvest ripening in the control group. Both $\mathrm{E} 2 \mathrm{H}(2.5)$ and $\mathrm{E} 2 \mathrm{H}$ (12.5) inhibited theß-carotene and lycopene increase, especially E2H (12.5) stopped the accumulation of $\beta$-carotene and lycopene totally in 18-72 h. Interestingly, the concentration of $\beta$-carotene showed more complex patterns than the lycopene in response to $\mathrm{E} 2 \mathrm{H}$ treatments. The increase and decrease of $\beta$-carotene in response to $\mathrm{E} 2 \mathrm{H}$ treatments formed "peaks" at $36 \mathrm{~h}$ in $\mathrm{E} 2 \mathrm{H}(2.5)$ group and $6 \mathrm{~h}$ in the $\mathrm{E} 2 \mathrm{H}$ (12.5) group separately (Figure $4 \mathrm{C}$ and D).

\subsection{Effects of E-2-hexenal on LOX and HPL gene expressions}

The responses of both $L O X C$ and $H P L$ to E2H were fast $(6 \mathrm{~h})$, but they showed obviously different patterns (Figure 5).

The expression of $L O X$ upregulated during postharvest colour transformation in the control group. The E2H (2.5) group showed upregulation of $L O X$ than the control at $6 \mathrm{~h}$, and downregulation than the control at 36$72 \mathrm{~h}$. The E2H (12.5) group showed upregulation of $L O X$ than the control at $6-18 \mathrm{~h}$, and downregulation than the control at 36-72 h. Both E2H (2.5) and E2H (12.5) groups showed upregulation and then downregulation trends to form expression "peaks" at $6 \mathrm{~h}\left(2.5 \mu \mathrm{L} \mathrm{L}^{-1}\right)$ and 6-36 h $\left(12.5 \mu \mathrm{L} \mathrm{L}^{-1}\right)$ separately (Figure 5A).

The expression of $H P L$ downregulated during postharvest colour transformation in the control group. Both E2H (2.5) and E2H (12.5) groups showed sharply decreases since 6h and kept at lower expression levels than the control at all the time points (Figure $5 \mathrm{~B}$ ).

\subsection{Effects of E-2-hexenal on the titratable acids, ascorbic acids, soluble solids and malondialdehyde contents}

The E2H at both concentrations increased the contents of TA $(6 \mathrm{~h})$ and SSC (6 h and $36 \mathrm{~h})$ rapidly, and the effects of E2H (12.5) were more significant (Table 2). The E2H (2.5) (36-72h) and the E2H (12.5) (36h) both increased the contents of ascorbic acids in tomatoes, and the effects of $\mathrm{E} 2 \mathrm{H}(2.5)$ were more significant (Table 2). The E2H affected the MDA contents. The E2H (2.5) increased the MDA contents at 18-36 h while the $\mathrm{E} 2 \mathrm{H}(12.5)$ increased them at 6 and $36 \mathrm{~h}$, whereas at $72 \mathrm{~h}$, the contents of the MDA in the control group was higher than that of the two groups treated with E2H (Table 2).

\section{Discussion}

The contents of E2H increased by 4.3 times during the colour transformation of jujube (Song, Bi, Chen, Wu, Lyu \& Meng, 2019); E2H showed an exponential increase trend during the colour transformation of tomato (Wang, Baldwin, Luo, Zhao, Brecht \& Bai, 2019), then decreased significantly after the colour transformation (Liu, Meng, Chen, Yin, Hu, Shao, Liu, Zhu, Ye \& Wang, 2019). Coincidentally, the carotenoid accumulation and the E2H are both synthesized in the plastids (Joyard, Ferro, Masselon, Seigneurin-Berny, Salvi, Garin \& Rolland, 2010). There are regulatory relationships between carotenoids and E2H.

Before chloroplasts IMS transformation, carotenoids synthesis has started in grana and stroma thylakoids and then packed into IMS (Schweiggert et al. , 2011, Sun et al. , 2018). In papaya, tubular elements (te) were not found until the carotenoids accumulation in colored ripening stages (Schweiggertet al. , 2011). The red crystal remnants (cr) appeared only when induced by lycopene accumulation in the cultured juice vesicles of Newhall oranges (Lu et al. , 2017). Therefore, the IMS of the chloroplasts are regulated by carotenoids (Sun \& Li, 2020). 
Based on the above evidences and our results, it is hypothesis that the E2H plays critical role in carotenoids activated IMS transformation in the chloroplasts during tomato colour transformation.

Exogenous E2H inhibited tomato colour development with a concentration-dependent manner (Figure 1A). It established the connection of exogenous $\mathrm{E} 2 \mathrm{H}$ and the colour transformation. After E2H treatments in 72 $\mathrm{h}$, green pericarps and red columellas illustrated that $\mathrm{E} 2 \mathrm{H}$ can easily penetrate through connected tissues but locular gel physically or via signal transduction (Figure 1B). Instead of overall colour transformation from pink to red, patchy red areas were observed (Figure 1C). So E2H is more likely to suppress colour transformation through signal transduction than physical penetration.

Endogenous E2H increased during the colour transformation in jujube and tomato (Song et al. , 2019, Wang et al. , 2019), but why the exogenous E2H suppressed the colour transformation? It is indicated that exogenous E2H interfered the endogenous E2H functions during colour transformation. The exogenous E2H can be used as an interference tool to investigate the regulating mechanism among carotenoids accumulation (colour transformation), endogenous E2H and IMS transformation.

Ethylene initiates fruit ripening including colour changes. In the tomatoes pretreated or combine treated with the E2H, the colour development was not initiated by ET, whereas in the ET initiated tomatoes, the $\mathrm{E} 2 \mathrm{H}$ cannot reverse the initiated colour change (Figure 2). The E2H signal transduction is suggested to function downstream of ET. Similarly, in cherry tomato, rapid increase of ET was observed in 7-15 day whereas the rapid increase of E2H was in 15-22 d (Wu, Tao, Ai, Luo, Mao, Ying \& Li, 2018).

It is detected by TEM that the IMS of the chloroplasts (thylakoid membranes and envelope membranes) transformed to the characteristic structures of chromoplasts (tubular elements, plastoglobules and crystal remnants). These processes are conducted by membrane fusion or vesicles budding (Schweiggert et al. , 2011). According to the IMS transformation status (Figure 3I), four stages can be observed in the electron micrographs, including the chloroplast stage (S1) (Figure 3A), two transition stages (S3 and S4) (Figure 3B and C) and the chromoplast stage (S4) (Figure 3D and G). E2H accelerated the programed IMS transformation. The evidences included that (1) S1 and S2 plastids in the E2H group were not observed (Figure $3 \mathrm{E}, \mathrm{F}$ and $\mathrm{H}$ ); (2) fewer pg and no cr was observed (Figure $3 \mathrm{E}, \mathrm{F}$ and J). E2H have been reported to change the fatty acids composition in the membrane and accelerated the release of free fatty acids (Patrignani, Iucci, Belletti, Gardini, Guerzoni \& Lanciotti, 2008). The E2H biosynthesis process can also consume the free fatty acids released from the IMS (Beckett, Loreto, Velikova, Brunetti, Di Ferdinando, Tattini, Calfapietra \& Farrant, 2012). Base on the mechanism, the IMS transformation can be started by E2H when the carotenoids are not sufficiently accumulated. As a result, the tomato colour transformation were inhibited (Figure 1A).

By analogy, the endogenous E2H may acted downstream of carotenoids as a signal molecular in starting the IMS transformation when the carotenoids contents reached a threshold during fruit ripening. Combining the results above (Figures 1,2 and 3), a possible regulatory relationship was speculated: ethylene - carotenoids biosynthesis - E2H signaling - IMS transformation - more carotenoids accumulation.

The results of the pigments also support the above hypothesis (Figure 4). The a* value was used as the parameter indicating the colour development dynamics. The decrease of chlorophyll and the increase of lycopene are consistent with the results of a ${ }^{*}$ value (Figure $4 \mathrm{~A}-\mathrm{C}$ ). It is indicated that the chlorophyll and lycopene contents determine the colour of the tomatoes.

The low level E2H delayed the chlorophyll decline and lycopene increase, while the high level E2H completely prevented the changes of chlorophyll and lycopene contents (Figure 4A-C). A series of key proteins involved in

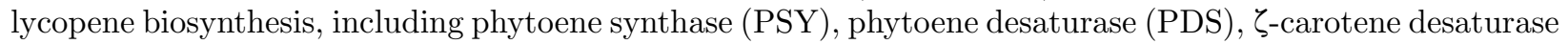

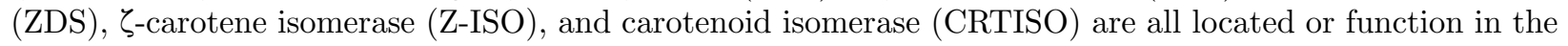
chloroplast IEM (Sun et al. , 2018, Zhou, McQuinn, Fei, Wolters, Van Eck, Brown, Giovannoni \& Li, 2011). When E2H accelerated the IEM transformation, some of the key proteins above possibly lost the functions as the structural basis disappeared, therefore the lycopene biosynthesis was delayed or completely prevented. The delayed chlorophyll decline can be explained similarly. The chlorophyll catabolism-related enzymes, which located in the thylakoid membrane and the structural basis disappeared. 
The lycopene $\beta$-cyclase (LycB) which located in the pg catalyzed the lycopene to synthesis $\beta$-carotene. It's worth noting that the $\beta$-carotene contents in the $\mathrm{E} 2 \mathrm{H}$ (2.5) and $\mathrm{E} 2 \mathrm{H}$ (12.5) groups were much higher than the control at $6 \mathrm{~h}$, and the $\mathrm{E} 2 \mathrm{H}$ (12.5) showed more significant elevation than the E2H (2.5) (Figure 4D). The results can be explained as the E2H accelerated the transformation of the IEM to pg at $6 \mathrm{~h}$, more LycB in the pg improved the synthesis of $\beta$-carotene, at the same time the pg in the control group were less formed (Fanciullino, Bidel \& Urban, 2014). In 36-72 h, the decrease of $\beta$-carotene contents in both of the E2H group can be explained as less pg structures formed than the control (Figure 4D).

Thylakoid membranes and IEM in the chloroplasts are enriched in galactolipids, in the fatty acid parts of the galactolipids, linolenic acid contents are up to $95 \%$ in some plant species. In response to biotic or abiotic stimuli, fatty acids including linolenic acids released from the thylakoid membranes or IEM (Joyard et al. , 2010). Although there is no direct evidence for the release of linolenic acid from the thylakoid membranes or IEM during tomato colour transformation, the linolenic acid in tomato reached a minimum content in the turning and pink periods (Saini, Zamany \& Keum, 2017).

In this study, the expression of lipoxygenase $\mathrm{C}$ gene ( $L O X C$ ) increased during colour transformation in the control group. E2H expedited the LOXC expression increase (Figure 5A). It is hypothesized that the release of linolenic acids may be accelerated by E2H because the LOXC is the key enzyme involve in the linolenic acids metabolism and produces hydroperoxyl-linolenoic acids. The expedited LOXC expression may explained the E2H accelerated IMS transformation because more linolenic acids were released and consumed by E2H treatments. Following that, the composition changes altered the IMS (Szilágyi, Selstam \& Åkerlund, 2008).

The decomposition of linolenic acids also produces endogenous E2H, and the 13-hydroperoxide lyase (13HPL) is the key enzyme involved. The $H P L$ expression was significantly decreased in the control group during colour transformation, and the exogenous E2H treatment further reduced the $H P L$ expression (Figure 5B). Considering that HPL is localized in the plastid outer envelope membrane (OEM), it is less affected by the transformations in the plastid inner membranes (Joyard et al. , 2010). Therefore, it is speculated that exogenous E2H feedback regulate the HPLexpression, which may be a mechanism to maintain endogenous E2H balance.

The quick increase responses $(6 \mathrm{~h})$ of TA and SCC to E2H treatments can be explained as the stress response (Table 2). In the following time, similar contents in of TA and SCC in the control and the E2H groups were detected (Table 2). It is indicated that the quality of tomato was less affected by E2H which may have less correlation with the IMS of the plastids.

The ascorbic acids are produced in mitochondria and enters other organelles including chloroplasts to function as antioxidants and coenzymes. Ascorbate acid transporters are located in the envelope membrane and the thylakoid membrane (Miyaji, Kuromori, Takeuchi, Yamaji, Yokosho, Shimazawa, Sugimoto, Omote, Ma, Shinozaki \& Moriyama, 2015). In this study, E2H accelerated the IEM and the thylakoid membrane transformation, the ascorbate acid transporters lost their structural basis, therefore ascorbic acids usage were inhibited. Therefore, the E2H increased the ascorbic acid content at 36-72h (Table 2).

The E2H treatments increased the MDA contents in part of the time points. In particular, the MDA contents in the E2H (2.5) group were higher than the E2H (12.5) at 18-36h. Based on the results, the effects of E2H on the IMS transformation may not base on the phytotoxicities, but the signaling activation (Table 2).

As shown in Figure 6, the mechanism of carotenoids activated inner membrane structures transformation in the chloroplasts during tomato fruit colour development were speculated. The E2H play critical role in this process. (I) the carotenoids are biosynthesis before IMS transform in the chloroplasts; (II) the carotenoids are packed into the IMS; (III) free linolenic acids are released from the IMS; (IV) LOXC decompose the free linolenic acids to produce hydroperoxy-linolenic acid; (V) HPL decompose the hydroperoxy-linolenic acid to produce E2Hs; (VI) The E2Hs are released inside or outside the plastid; (VII) The E2Hs altered the structure of the IMS; (VIII) the te, pg or cr structure in the chromoplasts form and accumulate more carotenoids; (IX) The E2Hs outside one plastid transfer to function in the neighbor plastids; (X) Excessive 
E2H feedback regulates the HPL enzyme to form a balanced level.

\section{Acknowledgments}

This work was supported by the Key Research and Development Program of Shandong Province [2019GNC106117]; the Youth Science and Technology Innovation Team of Shandong Province [2019KJF01], the Agricultural Industrial Technology System of Shandong Province [SDAIT-05-14] and the State Key Laboratory of Biobased Material and Green Papermaking, Qilu University of Technology, Shandong Academy of Sciences [ZZ20190410].

\section{Conflict of Interest Statement}

The work is an original research carried out by the authors. All authors have seen the manuscript and approved to submit to this journal. All Authors listed have contributed significantly to the work and agree to be in the author list.

This manuscript is an original contribution and has not been published or submitted for publication elsewhere in any language, in whole or in part. All the authors declare that no financial support or relationships that may pose conflict of interest by disclosing any financial arrangements they have with a company whose product figures prominently in the submitted manuscript or with a company making a competing product. And all the authors declare that no conflict relating to technology or methodology and no interest to disclose.

\section{References}

Arnon D.I. (1949) COPPER ENZYMES IN ISOLATED CHLOROPLASTS. POLYPHENOLOXIDASE IN BETA VULGARIS. Plant physiology, $24,1-15$.

Bai J., Baldwin E.A., Imahori Y., Kostenyuk I., Burns J. \& Brecht J.K. (2011) Chilling and heating may regulate C6 volatile aroma production by different mechanisms in tomato (Solanum lycopersicum) fruit. Postharvest Biology and Technology ,60, 111-120.

Bao H., Chen X., Lv S., Jiang P., Feng J., Fan P., Nie L. \& Li Y. (2015) Virus-induced gene silencing reveals control of reactive oxygen species accumulation and salt tolerance in tomato by $\gamma$-aminobutyric acid metabolic pathway. Plant, Cell \& Environment, 38 , 600-613.

Barr J., White W.S., Chen L., Bae H. \& Rodermel S. (2004) The GHOST terminal oxidase regulates developmental programming in tomato fruit. Plant, Cell \& Environment ,27 , 840-852.

Beckett M., Loreto F., Velikova V., Brunetti C., Di Ferdinando M., Tattini M., Calfapietra C. \& Farrant J.M. (2012) Photosynthetic limitations and volatile and non-volatile isoprenoids in the poikilochlorophyllous resurrection plant Xerophyta humilis during dehydration and rehydration. Plant, Cell Es Environment, 35 , 2061-2074.

Bonaventure G., Schuck S. \& Baldwin I.T. (2011) Revealing complexity and specificity in the activation of lipase-mediated oxylipin biosynthesis: a specific role of the Nicotiana attenuata GLA1 lipase in the activation of jasmonic acid biosynthesis in leaves and roots. Plant, Cell $\& 3$ Environment , 34, 1507-1520.

Fanciullino A.L., Bidel L.P.R. \& Urban L. (2014) Carotenoid responses to environmental stimuli: integrating redox and carbon controls into a fruit model. Plant, Cell \& Environment, 37 , 273-289.

Gao Y., Liu Y., Kan C., Chen M. \& Chen J. (2019) Changes of peel color and fruit quality in navel orange fruits under different storage methods. Scientia Horticulturae ,256 , 108522.

Hammerbacher A., Coutinho T.A. \& Gershenzon J. (2019) Roles of plant volatiles in defence against microbial pathogens and microbial exploitation of volatiles.Plant, Cell \&3 Environment , 42 , 2827-2843.

Joyard J., Ferro M., Masselon C., Seigneurin-Berny D., Salvi D., Garin J. \& Rolland N. (2010) Chloroplast proteomics highlights the subcellular compartmentation of lipid metabolism. Progress in Lipid Research, $49,128-158$. 
Liu H., Meng F., Chen S., Yin T., Hu S., Shao Z., Liu Y., Zhu C., Ye H. \& Wang Q. (2019) Ethanol treatment improves the sensory quality of cherry tomatoes stored at room temperature. Food Chem, 298 , 125069 .

Livak K.J. \& Schmittgen T.D. (2001) Analysis of relative gene expression data using real-time quantitative PCR and the 2(-Delta Delta C(T)) Method. Methods , 25 , 402-408.

Lu P.J., Wang C.Y., Yin T.T., Zhong S.L., Grierson D., Chen K.S. \& Xu C.J. (2017) Cytological and molecular characterization of carotenoid accumulation in normal and high-lycopene mutant oranges. Sci Rep , 7,761 .

Ma J., Xiao R., Li J., Li J., Shi B., Liang Y., Lu W. \& Chen L. (2011) Headspace solid-phase microextraction with on-fiber derivatization for the determination of aldehydes in algae by gas chromatography-mass spectrometry. Journal of Separation Science, 34, 1477-1483.

Miyaji T., Kuromori T., Takeuchi Y., Yamaji N., Yokosho K., Shimazawa A., Sugimoto E., Omote H., Ma J.F., Shinozaki K. \& Moriyama Y. (2015) AtPHT4;4 is a chloroplast-localized ascorbate transporter in Arabidopsis. Nature communications ,6 , 5928-5928.

Mumm R., Posthumus M.A. \& Dicke M. (2008) Significance of terpenoids in induced indirect plant defence against herbivorous arthropods. Plant, Cell \& Environment ,31 , 575-585.

Patrignani F., Iucci L., Belletti N., Gardini F., Guerzoni M.E. \& Lanciotti R. (2008) Effects of sub-lethal concentrations of hexanal and 2-(E)-hexenal on membrane fatty acid composition and volatile compounds of Listeria monocytogenes, Staphylococcus aureus, Salmonella enteritidis and Escherichia coli.International Journal of Food Microbiology, 123, 1-8.

Ronen G., Cohen M., Zamir D. \& Hirschberg J. (1999) Regulation of carotenoid biosynthesis during tomato fruit development: expression of the gene for lycopene epsilon-cyclase is down-regulated during ripening and is elevated in the mutant Delta. The Plant Journal , 17, 341-351.

Saini R.K., Zamany A.J. \& Keum Y.-S. (2017) Ripening improves the content of carotenoid, $\alpha$-tocopherol, and polyunsaturated fatty acids in tomato (Solanum lycopersicum L.) fruits.3 Biotech , 7, 43.

Schweiggert R.M., Steingass C.B., Heller A., Esquivel P. \& Carle R. (2011) Characterization of chromoplasts and carotenoids of red- and yellow-fleshed papaya (Carica papaya L.). Planta, 234, 1031.

Song J., Bi J., Chen Q., Wu X., Lyu Y. \& Meng X. (2019) Assessment of sugar content, fatty acids, free amino acids, and volatile profiles in jujube fruits at different ripening stages. Food Chem, 270, 344-352.

Sun F., Zhang P., Guo M., Yu W. \& Chen K. (2013) Burdock fructooligosaccharide induces fungal resistance in postharvest Kyoho grapes by activating the salicylic acid-dependent pathway and inhibiting browning. Food Chem, 138 , 539-546.

Sun T. \& Li L. (2020) Toward the 'golden' era: The status in uncovering the regulatory control of carotenoid accumulation in plants. Plant Science, 290, 110331.

Sun T., Yuan H., Cao H., Yazdani M., Tadmor Y. \& Li L. (2018) Carotenoid Metabolism in Plants: The Role of Plastids. Molecular Plant, $11,58-74$.

Szilágyi A., Selstam E. \& Åkerlund H.-E. (2008) Laurdan fluorescence spectroscopy in the thylakoid bilayer: The effect of violaxanthin to zeaxanthin conversion on the galactolipid dominated lipid environment. Biochimica et Biophysica Acta (BBA) - Biomembranes , 1778 , 348-355.

Wang L., Baldwin E., Luo W., Zhao W., Brecht J. \& Bai J. (2019) Key tomato volatile compounds during postharvest ripening in response to chilling and pre-chilling heat treatments. Postharvest Biology and Technology , 154, 11-20. 
Wei W., Lv P., Xia Q., Tan F., Sun F., Yu W., Jia L. \& Cheng J. (2017) Fresh-keeping effects of three types of modified atmosphere packaging of pine-mushrooms.Postharvest Biology and Technology , 132, 62-70.

Wu Q., Tao X., Ai X., Luo Z., Mao L., Ying T. \& Li L. (2018) Effect of exogenous auxin on aroma volatiles of cherry tomato (Solanum lycopersicum L.) fruit during postharvest ripening. Postharvest Biology and Technology , 146 , 108-116.

Yang Y., Wang X., Tan F., Fu M. \& Sun F. (2019) Burdock fructooligosaccharides inhibits postharvest colour development in grape skins by altering phenylpropanoid fluxes from anthocyanin to the resistance-related phenolic substances.Australian Journal of Grape and Wine Research , 25 , 307-315.

Zhou X., McQuinn R., Fei Z., Wolters A.-M.A., Van Eck J., Brown C., Giovannoni J.J. \& Li L.I. (2011) Regulatory control of high levels of carotenoid accumulation in potato tubers. Plant, Cell \& Environment, 34, 1020-1030.

Table 1. Sequence of primers

\begin{tabular}{lll}
\hline Gene name (Gene ID) & Primers $\left(5^{\prime}-3^{\prime}\right)$ & References \\
\hline Actin (AB199316) & Forward: AGGAACACCCT- & (Bao, Chen, Lv, Jiang, Feng, Fan, \\
& GTTCTCCTGACTG Reverse: & Nie \& Li, 2015) \\
& CAGAGAAAGCACAGCCTGGATAG & \\
LOXC (U37839) & Forward: AAATGAGCACCA- & (Bai, Baldwin, Imahori, \\
& CAAGGAAATGTAT Reverse: & Kostenyuk, Burns \& Brecht, \\
HPL (AF230372) & ACCCAAGAGTTGCATGTAATT2A11) \\
& Forward: GTCCACCAGTAC- \\
& CAAGTCAATATGC Reverse: \\
& GCTCCCTTTCTTGATTCGTAA \\
\hline
\end{tabular}

Table 2 The titratable acids, ascorbic acids, soluble solids and malondialdehyde contents in response to $E$-2-hexenal treatments

\begin{tabular}{llllll}
\hline Time $(\mathrm{h})$ & $\begin{array}{l}E \text {-2-hexenal }(\mu \mathrm{L} \\
\left.\mathrm{L}^{-1}\right)\end{array}$ & $\begin{array}{l}\text { Titratable acids } \\
(\%)\end{array}$ & $\begin{array}{l}\text { Ascorbic acids } \\
\left(\mathrm{mg} 100 \mathrm{~g}^{-1}\right)\end{array}$ & $\begin{array}{l}\text { Soluble solids } \\
\text { content }(\%)\end{array}$ & $\begin{array}{l}\text { Malondialdehyde } \\
\left(10^{-4} \mu \mathrm{mol} \mathrm{g}^{-1}\right)\end{array}$ \\
\hline 06183672 & 02.512 .50 & $0.33 \pm 0.01 \mathrm{a}$ & $9.97 \pm 0.11 \mathrm{a}$ & $3.47 \pm 0.04 \mathrm{a}$ & $4.97 \pm 0.53 \mathrm{a}$ \\
& 2.512 .502 .5 & $0.33 \pm 0.01 \mathrm{a}$ & $9.97 \pm 0.11 \mathrm{a}$ & $3.47 \pm 0.04 \mathrm{a}$ & $4.97 \pm 0.53 \mathrm{a}$ \\
& 12.502 .512 .5 & $0.33 \pm 0.01 \mathrm{a}$ & $9.97 \pm 0.11 \mathrm{a}$ & $3.47 \pm 0.04 \mathrm{a}$ & $4.97 \pm 0.53 \mathrm{a}$ \\
& 02.512 .5 & $0.34 \pm 0.01 \mathrm{~b}$ & $10.50 \pm 0.47 \mathrm{a}$ & $2.74 \pm 0.06 \mathrm{~b}$ & $5.56 \pm 0.39 \mathrm{~b}$ \\
& $0.39 \pm 0.01 \mathrm{ab}$ & $11.25 \pm 0.24 \mathrm{a}$ & $3.34 \pm 0.16 \mathrm{a}$ & $5.42 \pm 0.46 \mathrm{~b}$ \\
& $0.42 \pm 0.01 \mathrm{a}$ & $10.25 \pm 0.78 \mathrm{a}$ & $3.63 \pm 0.05 \mathrm{a}$ & $6.96 \pm 0.40 \mathrm{a}$ \\
& $0.37 \pm 0.01 \mathrm{a}$ & $11.24 \pm 0.63 \mathrm{a}$ & $3.18 \pm 0.09 \mathrm{a}$ & $3.68 \pm 0.46 \mathrm{ab}$ \\
& $0.39 \pm 0.01 \mathrm{a}$ & $12.00 \pm 0.09 \mathrm{a}$ & $3.40 \pm 0.31 \mathrm{a}$ & $4.05 \pm 0.34 \mathrm{a}$ \\
& $0.41 \pm 0.02 \mathrm{a}$ & $10.70 \pm 0.79 \mathrm{a}$ & $3.44 \pm 0.17 \mathrm{a}$ & $3.05 \pm 0.45 \mathrm{~b}$ \\
& $0.40 \pm 0.01 \mathrm{a}$ & $9.03 \pm 0.38 \mathrm{~b}$ & $3.35 \pm 0.17 \mathrm{~b}$ & $2.33 \pm 0.54 \mathrm{~b}$ \\
& $0.38 \pm 0.01 \mathrm{a}$ & $12.30 \pm 1.01 \mathrm{a}$ & $3.58 \pm 0.14 \mathrm{ab}$ & $4.31 \pm 0.13 \mathrm{a}$ \\
& $0.44 \pm 0.03 \mathrm{a}$ & $11.42 \pm 0.15 \mathrm{a}$ & $3.85 \pm 0.05 \mathrm{a}$ & $3.66 \pm 0.60 \mathrm{a}$ \\
& $0.44 \pm 0.01 \mathrm{a}$ & $9.44 \pm 0.46 \mathrm{~b}$ & $3.51 \pm 0.11 \mathrm{a}$ & $7.56 \pm 0.73 \mathrm{a}$ \\
& $0.39 \pm 0.01 \mathrm{a}$ & $11.90 \pm 1.22 \mathrm{a}$ & $3.76 \pm 0.18 \mathrm{a}$ & $6.06 \pm 0.49 \mathrm{~b}$ \\
& $0.42 \pm 0.02 \mathrm{a}$ & $8.48 \pm 0.08 \mathrm{~b}$ & $3.36 \pm 0.20 \mathrm{a}$ & $6.49 \pm 0.54 \mathrm{~b}$ \\
\hline
\end{tabular}

Figure legends 
Figure 1. Effects of $E$-2-hexenal $\left(0.5 \mu \mathrm{L} \mathrm{L}^{-1}, 2.5 \mu \mathrm{L} \mathrm{L}^{-1}, 12.5 \mu \mathrm{L} \mathrm{L}^{-1}, 25 \mu \mathrm{L} \mathrm{L}^{-1} \mathrm{E} 2 \mathrm{H}\right.$ liquid volume / sealed space volume) and ethylene (12 $\left.\mathrm{mg} \mathrm{L}^{-1}\right)$ on tomato colour development at $0 \mathrm{~h}$ and $72 \mathrm{~h}$ after treatment (A). Effects of $E$-2-hexenal $\left(12.5 \mu \mathrm{L} \mathrm{L}^{-1}\right)$ on the longitudinal section appearances (B) and the surface colour characteristics $(\mathrm{C})$ of the tomatoes at $72 \mathrm{~h}$. The storage temperature was at $20{ }^{\circ} \mathrm{C}$.

Figure 2. The Photos of tomato treated with E -2-hexenal (E2H) (24 h), ethylene (ET) (24 h), ET (12 $\mathrm{h})$ and then E2H $(12 \mathrm{~h}), \mathrm{E} 2 \mathrm{H}(12 \mathrm{~h})$ and then ET $(12 \mathrm{~h})$ and combined E2H and ET $(24 \mathrm{~h})$ at $72 \mathrm{~h}$. The concentrations of the treatments used were $\mathrm{E} 2 \mathrm{H}\left(12.5 \mu \mathrm{L} \mathrm{L}^{-1}\right)$ and $\mathrm{ET}\left(12 \mathrm{mg} \mathrm{L}^{-1}\right)$. The storage temperature was at $20^{\circ} \mathrm{C}$.

Figure 3. Electron micrographs of plastids during transformation of chloroplasts to chromoplasts at $72 \mathrm{~h}$ pretreated with $E$-2-hexenal (A-D) and the control (E and F).

Standards for four stages of the plastids were listed in the table (I). Four stages (S1: chloroplast; S2: transition stages 1; S3: transition stages 2 and S4: chromosome) were observed and counted in all the cells captured. The statistically results of the proportions in S1, S2, S3 and S4 stages at $72 \mathrm{~h}$ pretreated with $E$ -2-hexenal $(\mathrm{H})$ and the control $(\mathrm{G})$ were analyzed. The plastoglobules $(\mathrm{pg})$ count per plastid were compared between $E$-2-hexenal group and the control $(\mathrm{J})$. The $E$-2-hexenal treatments was $12.5 \mu \mathrm{L} \mathrm{L}^{-1}$ and the storage temperature was at $20^{\circ} \mathrm{C}$. The inner membranes (im), tubular elements (te), plastoglobules (pg) and crystal remnants (cr) were marked in the photos in red arrows.

Figure 4. Effect of $E$-2-hexenal $\left(2.5 \mu \mathrm{L} \mathrm{L}^{-1}\right.$ and $\left.12.5 \mu \mathrm{L} \mathrm{L}^{-1}\right)$ on the a* value (A); the chlorophyll (B), $\beta$-carotene (C) and lycopene (D) contents comparted to that of the control. The storage temperature was at $20^{\circ} \mathrm{C}$. Each value represents the mean of three replicates. Bars indicate the standard deviation $( \pm \mathrm{SD})$. The lower-case letters $(\mathrm{a}, \mathrm{b}$ and $\mathrm{c})$ indicates differences that are significant at $P<0.05$.

Figure 5. Relative expression of the LOXCs (A) andHPLs (B) genes detected in tomato pericarps in response to $E$-2-hexenal $\left(2.5 \mu \mathrm{L} \mathrm{L}^{-1}\right.$ and $\left.12.5 \mu \mathrm{L} \mathrm{L}^{-1}\right)$ and the control. The storage temperature was at 20 ${ }^{\circ} \mathrm{C}$. Histograms representing the average of three biological samples that were independently assessed. Data

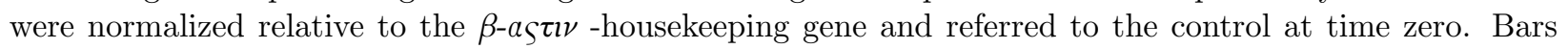
indicate the standard deviation $( \pm \mathrm{SD})$. The lower-case letters $(\mathrm{a}, \mathrm{b}$ and $\mathrm{c})$ indicates differences that are significant at $P<0.05$.

Figure 6. Scheme of the possible mechanisms of carotenoids activated inner membrane structures transformation in the chloroplasts during tomato fruit colour development.

Ten steps were shown at the yellow spots with latin numbers: (I) the carotenoids are biosynthesis before IMS transform in the chloroplasts; (II) the carotenoids are packed into the IMS; (III) free linolenic acids are released from the IMS; (IV) LOXC decompose the free linolenic acids to produce hydroperoxy-linolenic acid; (V) HPL decompose the hydroperoxy-linolenic acid to produce E2Hs; (VI) The E2Hs are released inside or outside the plastid; (VII) The E2Hs altered the structure of the IMS; (VIII) the te, pg or cr structure in the chromoplasts form and accumulate more carotenoids; (IX) The E2Hs outside one plastid transfer to function in the neighbor plastids; (X) Excessive E2H feedback regulates the HPL enzyme to form a balanced level. 


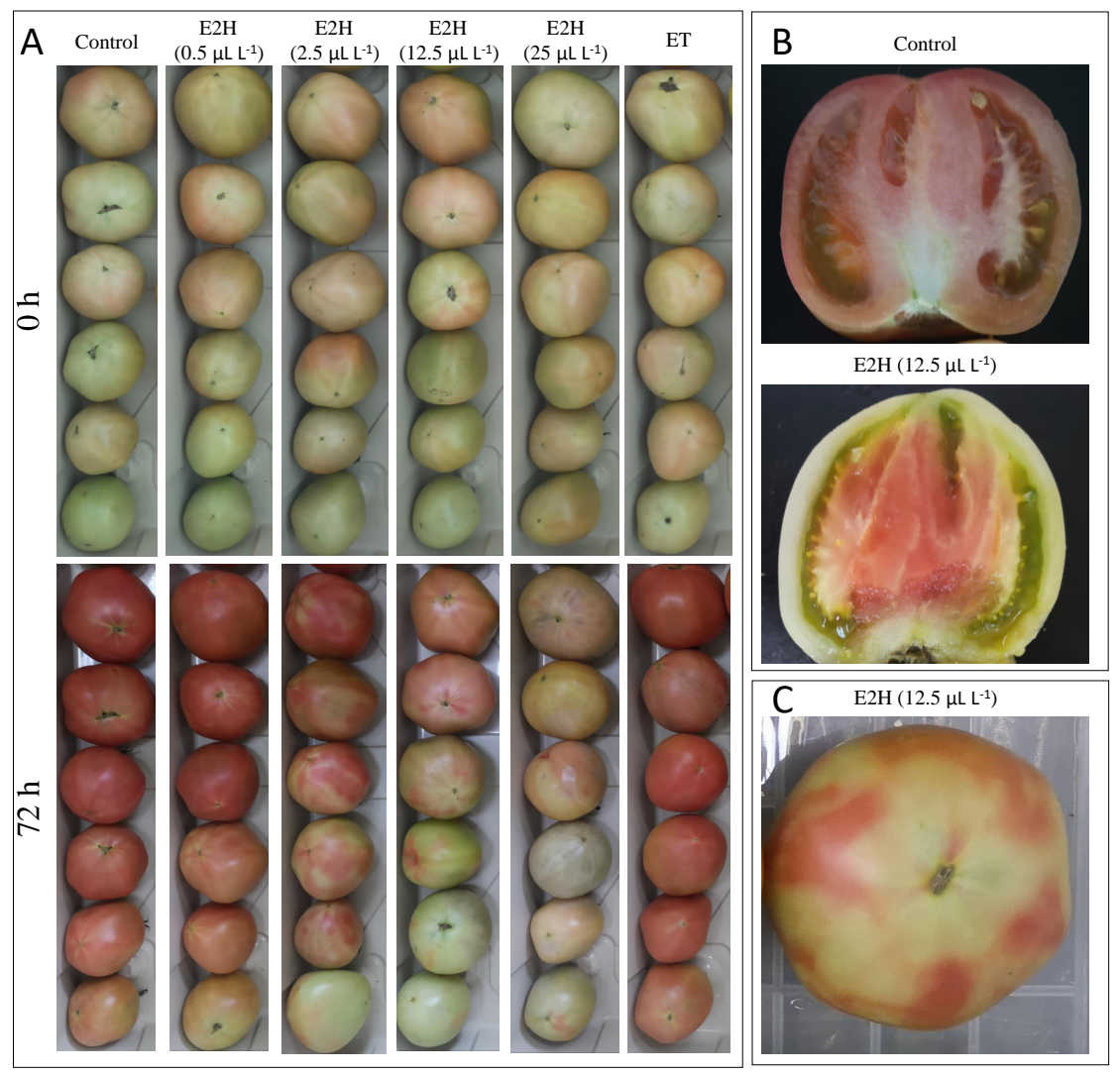



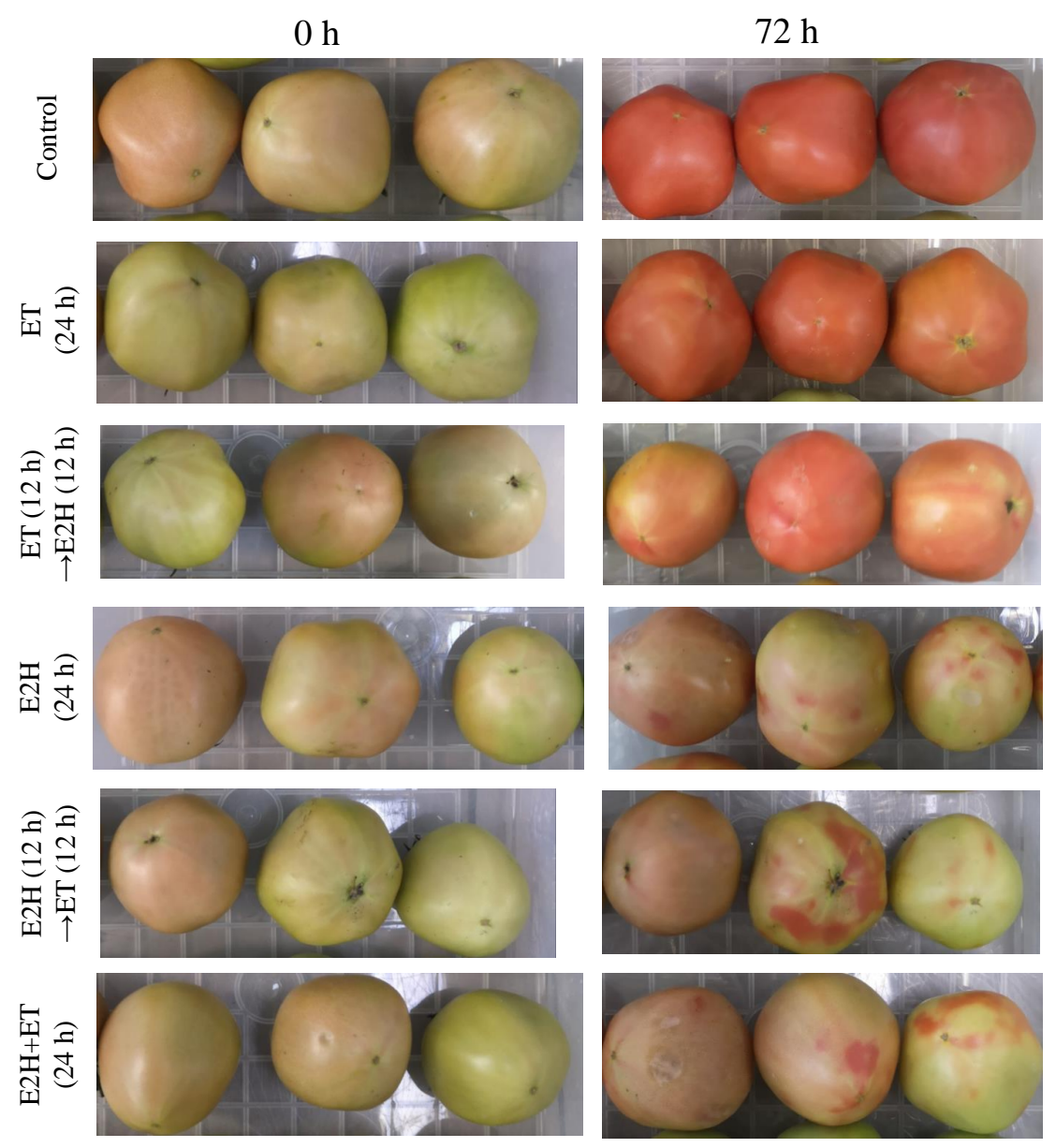


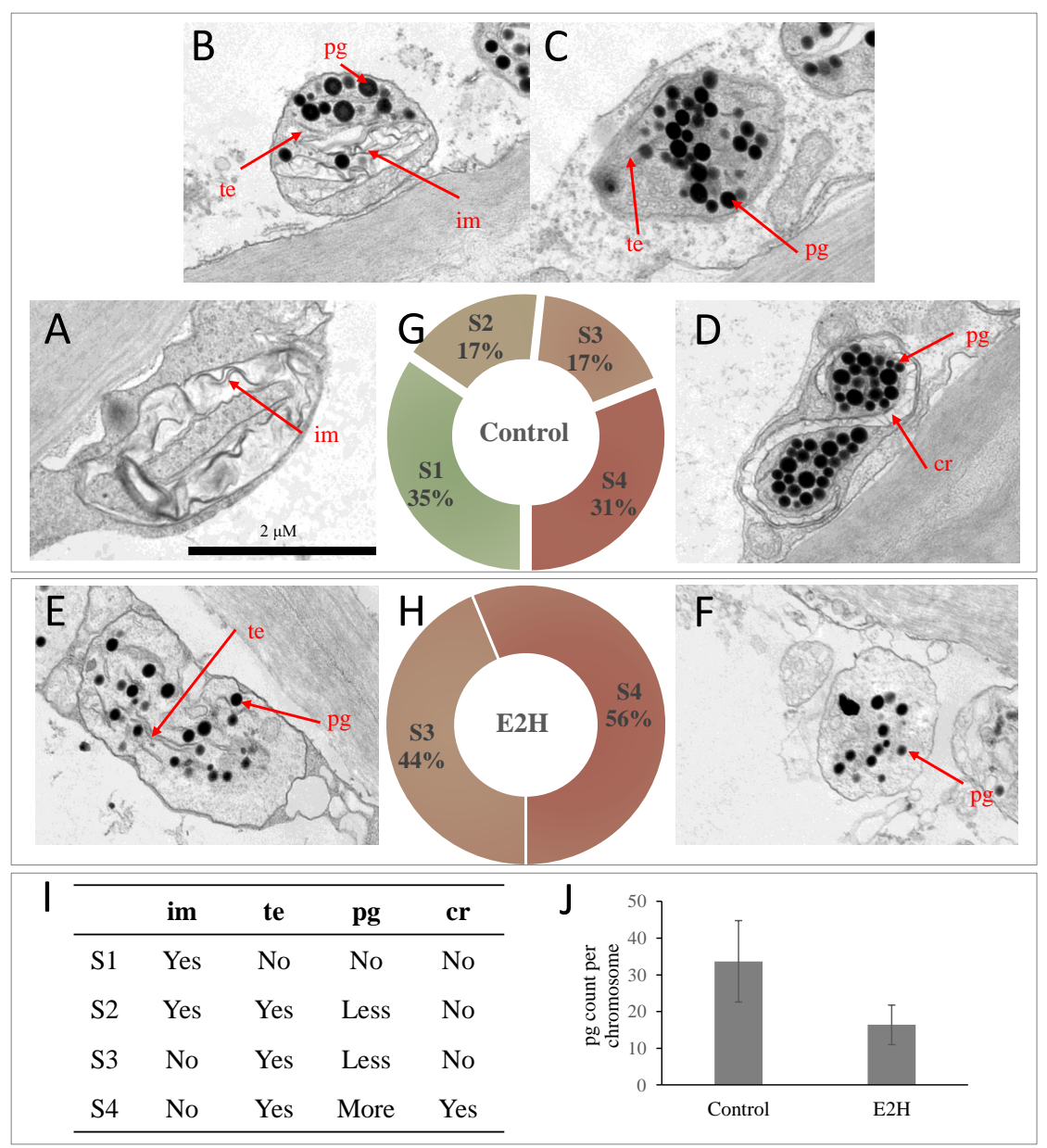



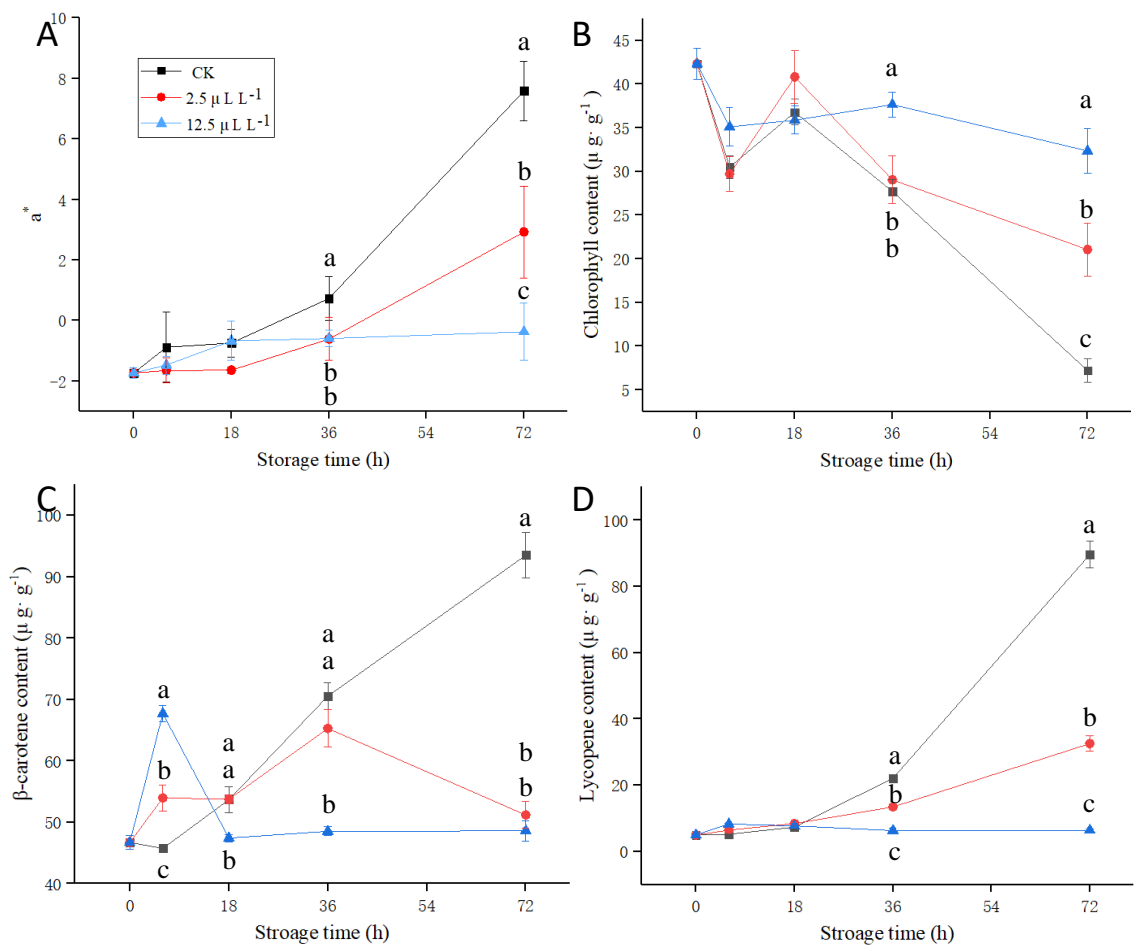

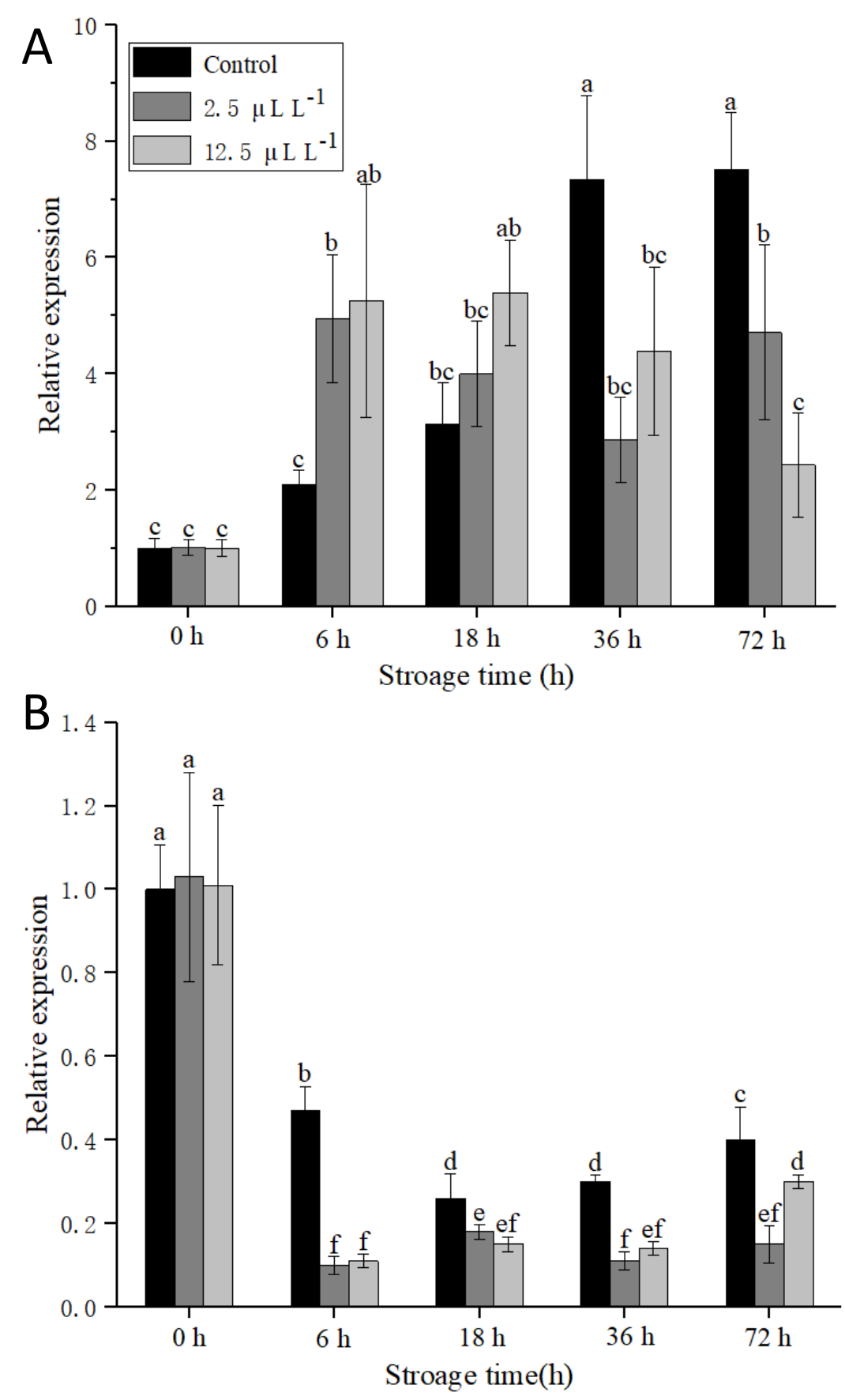


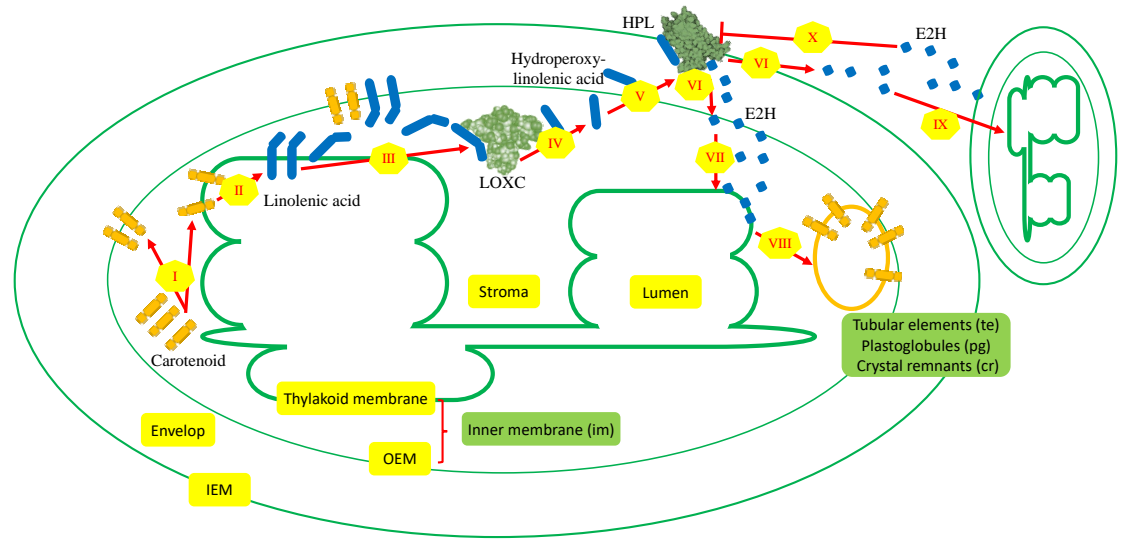

